\title{
Study on the Characteristics of ICP-PECVD Boron Silicate Glasses Dependent on Diborane Flux
}

\author{
J. Engelhardt, ${ }^{\mathrm{z}}$ G. Fitzky, G. Hahn, and B. Terheiden \\ Photovoltaics, University of Konstanz, Konstanz 78464, Germany
}

\begin{abstract}
Boron silicate glasses from inductively-coupled plasma-enhanced chemical vapor deposition are investigated by variation of the diborane flux applied during deposition. Fast Fourier transform infrared spectroscopy measurements of B related peaks calibrated by inductively-coupled optical emission spectroscopy is used to determine the B concentration in the deposited films. Optical, chemical, and electric properties of the boron silicate glasses before and after a high temperature step, as well as of the resulting emitter layer, are discussed. Changes in the molecular composition of the B related bonding structure of the films during the high temperature step are found to be responsible for the properties of the emitter layers as well as the boron silicate glass films. Three corresponding regimes of the film growth depending on the diborane flux are identified and characterized. The formation of a boron-rich layer (BRL) is indirectly shown to be the limiting factor for emitter functions and influencing the corresponding properties under given conditions, i.e., at higher diborane fluxes.
\end{abstract}

Boron silicate glasses (BSG), known also as B doped/doping/ containing silicon oxide layers/films $\left(\mathrm{SiO}_{\mathrm{x}}: \mathrm{B}\right)$, have been used in a large variety of applications for a long time. As dielectric layers with no to moderate conductivity, they are used in semiconductor structures as insulator or conductive layers. ' Currently, due to their doping source property, they are more commonly used for doped layer diffusion from solid-state diffusion sources. ${ }^{2-5}$ In semiconductor science, especially in photovoltaics, BSG films are utilized to form emitter layers on semiconductor substrates for $\mathrm{p}-\mathrm{n}$ junctions. BSG layers can thereby be deposited by various techniques, such as gas tube diffusion (i.e., $\mathrm{BBr}_{3}{ }^{6,7}$ or $\mathrm{BCl}_{3}{ }^{8}$ sources), spin-on coating, ${ }^{9}$ printing ${ }^{10}$ or sputtering. " As of late, doped chemical vapor deposited (CVD) films are more and more used commercially as doping sources ${ }^{12-16}$ due to the possibility to be easily structured, ${ }^{13,14}$ conveniently controlled, to allow to separate deposition and diffusion, ${ }^{17-20}$ as well as to serve as a multi-purpose layer ${ }^{21}$ compared to other techniques mentioned. While, e.g., BSG growth during gas tube diffusion (i.e., $\mathrm{BBr}_{3}$ ) is only possible at higher temperatures and with the inseparable simultaneous dopant diffusion, doped CVD layers allow for more freedom of parameter control. The growth of CVD BSG layers does not consume the substrate, it can be done at any temperature, during deposition the molecular bond structure can be easily adjusted and there is no diffusion of dopants into the substrate during deposition. Inductively coupled plasma - plasma-enhanced CVD (ICP-PECVD), ${ }^{22-26}$ is a lowpressure CVD tool with an inductively coupled plasma enhancing the semi/non-directional chemical vapor deposition on the substrates. ICP technology thereby allows for lower plasma damage to the substrate during deposition, adjustable $\mathrm{H}$ content and high density of BSG films. Considering the need for an undamaged $\mathrm{Si}$ substrate and $\mathrm{H}$ to passivate recombination active defects in the bulk $\mathrm{Si}$, ICP-PECVD BSG films are advantageous for photovoltaics and other similar applications. To determine the influence of these CVD parameters and film properties, many studies have been carried out on the behavior of CVD BSG films during deposition and diffusion step, ${ }^{5}$ as well as on the formed doped layers (i.e., emitter layer). ${ }^{16,18}$ Thereby, focus lies on the molecular composition of BSG films to investigate, monitor, and control the various properties of BSG and its interaction with the Si substrate/interface. Commonly, fast Fourier transform infrared spectroscopy (FTIR) is applied to characterize the molecular bond densities, ${ }^{27,28}$ since ellipsometry only gives rudimentary information with too many open variables. FTIR is usually measured to give additional information or to take a deeper look into a single part of the experiment. In this case, FTIR is used to determine indirectly the B content of BSG layers in a fast and simple way compared to other common techniques (e.g., ICP optical emission spectroscopy (ICP-OES), secondary ion mass spectroscopy (SIMS), etc. ${ }^{29}$ ). When using BSG as a doping source, the question of emitter properties and interface structure arises. The presence of a B-rich layer (BRL) as a highly B doped $\mathrm{Si}$ layer ${ }^{2,30,31}$ with high recombination activity has to be considered for highly doped emitter layers formed from highly B containing BSG layers. Yet, e.g., as applied in photovoltaics, recombination activity should be as low as possible, even with the need for high doped emitter layers. Furthermore, due to the high concentration of substitutional B on $\mathrm{Si}$ sites in the BRL, the strain in the layer structure allows for defects and co-diffusing of $\mathrm{O}$ atoms in high concentrations. As such the BRL is suspected to influence the emitter formation significantly, $30,32,33$ being formed early during high temperature (high-T) diffusion steps. In situ avoidance or subsequent removal by, e.g., thermal oxidation ${ }^{12,30}$ or chemical etching ${ }^{34,35}$ is necessary for application of B emitters in electronics and photovoltaics.

\section{Experimental}

For sample preparation (process flow illustrated in Fig. 1; abbreviations cf. Table I) $200 \Omega \mathrm{cm}, \emptyset 150 \mathrm{~cm}$, n-type Float-Zone (FZ) wafers were laser cut in $5 \times 5 \mathrm{~cm}^{2}$ pieces. After a short polishing etching and subsequent cleaning step to remove the laser damage and native $\mathrm{SiO}_{2}$ layer, the samples were deposited with BSG films using our modified ICP-PECVD lab tool. The machine is a single-chamber reactor with a four wafer tray (6" square wafer size) positioned above the main reaction chamber for isotropic, semi-remote deposition from below. Plasma generation is realized by inductively coupling an externally generated magnetic field into the reaction gas zone in the low pressure chamber at $13.56 \mathrm{MHz}$. Thereby, the dielectric BSG layer was formed by reaction of silane $\left(\mathrm{SiH}_{4}\right)$, carbon dioxide $\left(\mathrm{CO}_{2}\right)$ and $\mathrm{H}_{2}$ diluted diborane $\left(\mathrm{B}_{2} \mathrm{H}_{6}: \mathrm{H}_{2}\right)$. Whereas the $\mathrm{SiH}_{4}$ and $\mathrm{CO}_{2}$ fluxes were kept constant, the diborane flux $\mathrm{Q}_{\mathrm{B} 2 \mathrm{H} 6: \mathrm{H} 2}$ was varied from 400 to $1000 \mathrm{sccm}$. After double-sided deposition, half of the samples were diffused in nitrogen atmosphere using a commercial tube diffusion furnace (centrotherm E 1200 HAT 300-4) at a common B diffusion

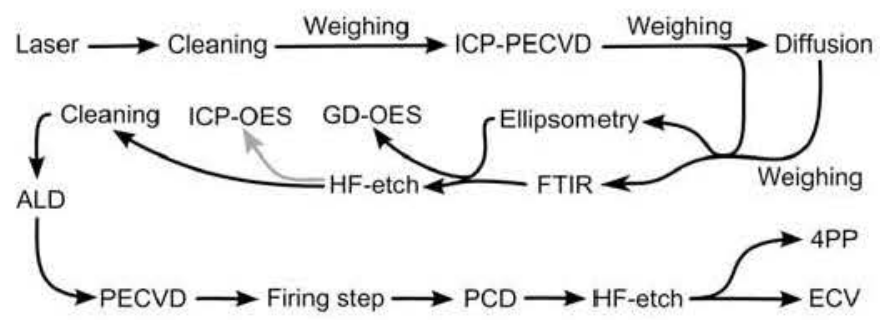

Figure 1. Schematic depiction of sample process flow illustrating variations in processing for as- and non-diffused samples. Refer to Experimental section for detailed description of process steps. 
Table I. Used definitions and descriptions overview including respective symbols and units.

Definition/Description

Symbol

Unit

B containing Si oxide

B-rich layer

B silicate glass

$\mathrm{SiO}_{\mathrm{x}}: \mathrm{B}$

BRL

B tribromide

BSG

$\mathrm{BBr}_{3}$

Diborane

Electro-chemical voltage (measurement)

Fourier transform infrared (spectroscopy)

Inductively coupled plasma - plasma enhanced chemical vapor deposition

Inductively coupled plasma - optical emission spectroscopy

Silane

Atomic density

Atomic mass, $\mathrm{Si}$

Atomic mass, B

Avogadro constant

B concentration

$B$ content, gas weighed

$B$ content, gas and mass weighed

$B$ content, ICP-OES

$\mathrm{B}$ doping concentration

$\mathrm{B}_{2} \mathrm{H}_{6}$ flux, absolute

$\mathrm{B}_{2} \mathrm{H}_{6}$ flux, diluted in $\mathrm{H}_{2}$

Depth (emitter)

Emitter saturation current density

Film density

Film thickness

FTIR signal intensity, absorbance

Molar mass, $\mathrm{SiO}_{2}$

Molar mass, $\mathrm{SiO}_{\mathrm{x}}: \mathrm{B}$

Molecular density

Normalized FTIR peak area

Oxygen concentration

Refractive index

Relative $\mathrm{B}_{2} \mathrm{H}_{6}$ concentration in $\mathrm{B}_{2} \mathrm{H}_{6}: \mathrm{H}_{2}$

Scaled FTIR peak area

Sheet resistance

Si concentration

$\mathrm{SiH}_{4}$ flux, absolute

Surface doping concentration

Wavenumber

$\mathrm{B}_{2} \mathrm{H}_{6}$

FTIR

ICP-PECVD

ICP-OES

$\mathrm{SiH}_{4}$

$\rho_{\mathrm{at}}$

$\mathrm{m}_{\mathrm{a} . \mathrm{Si}}$

$\mathrm{m}_{\mathrm{a} \cdot \mathrm{B}}$

$\mathrm{N}_{\mathrm{A}}$

CICP-OES

$\mathrm{ct}_{\mathrm{g}}$

$\mathrm{ct}_{\mathrm{g} . \mathrm{m}}$

ctICP-OES

$\mathrm{c}_{\mathrm{B}}$

$\mathrm{Q}_{\text {B2H6 }}$

QB2H6:H2

D

joE

$\rho$

d

I

$\mathrm{M}_{\mathrm{SiO} 2}$

MSiOx:B

$\rho_{\text {mol }}$

$\mathrm{I}_{\mathrm{N}}$

$\mathrm{c}_{\mathrm{O}}$

n

c\%.B2H6

Is

$\mathrm{R}_{\text {Sheet }}$

$\mathrm{c}_{\mathrm{Si}}$

$\mathrm{QSiH}_{4}$

$\mathrm{N}_{\text {Sur }}$

$\tilde{v}$

$\left[\mathrm{cm}^{-3}\right]$

[u]

[u]

[ $\left.\mathrm{mol}^{-1}\right]$

$\left[\mathrm{cm}^{-3}\right]$

[wt\%]

[wt\%]

[wt \%]

$\left[\mathrm{cm}^{-3}\right]$

[sccm]

[sccm]

[ $\mu \mathrm{m}]$

[fA. $\mathrm{cm}^{-2}$ ]

$\left[\mathrm{g} \cdot \mathrm{cm}^{-3}\right]$

[nm]

[a.u.]

$\left[\mathrm{g} \cdot \mathrm{mol}^{-1}\right]$

$\left[\mathrm{g} \cdot \mathrm{mol}^{-1}\right]$

$\left[\mathrm{cm}^{-3}\right]$

[-]

$\left[\mathrm{cm}^{-3}\right]$

[-]

[\%]

[-]

$\left[\Omega \cdot \square^{-1}\right]$

$\left[\mathrm{cm}^{-3}\right]$

[sccm]

$\left[\mathrm{cm}^{-3}\right]$

$\left[\mathrm{cm}^{-1}\right]$

temperature of $930^{\circ} \mathrm{C}$ and duration of $100 \mathrm{~min}$. Before deposition, after deposition, and after the diffusion step all samples were weighed (Mettler Toledo AT21 Comparator scale with an accuracy of $1 \mu \mathrm{g}$ ) to determine the change in film density $\rho$ during processing. The BSG on all samples was analyzed regarding its optical properties - refractive index $\mathrm{n}$ and thickness $\mathrm{d}$ - by ellipsometry (W-Vase ellipsometer from J.A. Woollam) and the molecular bond structure - absorbance intensity signal I depending on wavenumber $\tilde{v}$ - by FTIR (Vertex 80 from Bruker Optics). Furthermore, GD-OES measurements (GDA $750 \mathrm{HR}$ from Spectruma Analytics $\mathrm{GmbH}$ ) were carried out to determine the concentration profiles for $\mathrm{B}, \mathrm{Si}$ and $\mathrm{O}$ for all $\mathrm{BSG}$ layers of as- and non-diffused samples. Afterwards, the doped layers on all samples were removed using hydrofluoric acid (HF) to be processed by an ICP-OES tool (720 ICP-OES from Agilent Technologies) to determine the $\mathrm{B}$ concentration $\mathrm{C}_{\mathrm{ICP} \text {-OES }}$ within the layers before and after the diffusion step. In the following step, the BSG was removed from the diffused samples within a standard cleaning step and the surface was re-passivated by an aluminum oxide $\left(\mathrm{Al}_{2} \mathrm{O}_{3}\right)$ /silicon nitride $\left(\mathrm{SiN}_{\mathrm{x}}: \mathrm{H}\right)$ dielectric stack, deposited at around $300^{\circ} \mathrm{C}$ by atomic layer deposition (ALD; FlexAL from Oxford Instruments) and at around $400^{\circ} \mathrm{C}$ by remote PECVD (SiNA; Roth \& Rau), respectively. The samples were subsequently fired in a belt furnace at around $850^{\circ} \mathrm{C}$ sample temperature (DO 9.700-300-FF-CANtrol from Centrotherm) to activate the surface passivation, and the samples' emitter saturation current density $\mathrm{j}_{\mathrm{OE}}{ }^{36}$ was measured using a Sinton WCT120 Lifetime
Tester (Sinton Instruments). The dielectric layer stack was removed by $\mathrm{HF}$ etch - as before the BSG - for sheet resistance $\mathrm{R}_{\text {Sheet }}$ measurement by four-point probe (4PP) and electrochemical capacitance voltage (ECV) (Wafer Profiler CVP21 from WEP) measurement. The latter was also used to determine the emitter profile (B doping concentration $\mathrm{c}_{\mathrm{B}}$ depending on depth $\mathrm{D}$ ) and the surface doping concentration $\mathrm{N}_{\text {Surf }}$. Thereby, the firing step and cleaning steps for passivation, deposition and removal had no influence on the subsequent measurements. Furthermore, no capping layers were used on top of the BSG during diffusion step. Commonly, capping layers are used to prevent out-diffusion of B into the furnace atmosphere and in-diffusion of contaminants, i.e., other dopants. In this case, the capping layer was deliberately omitted considering the lack of possible in-diffusion of other dopants. Common capping layers would otherwise include $\mathrm{SiO}_{x}$, $\mathrm{SiN}_{\mathrm{x}}: \mathrm{H}$ and $\mathrm{SiO}_{\mathrm{x}} \mathrm{N}_{\mathrm{y}} \cdot 37,38$

\section{Results and Discussion}

The increase of the $\mathrm{B}_{2} \mathrm{H}_{6}: \mathrm{H}_{2}$ flux $\mathrm{Q}_{\mathrm{B} 2 \mathrm{H} 6: \mathrm{H}_{2}}$ fraction on the total gas flux for different ICP-PECV-depositions of BSG layers leads to significant changes in the physical properties of the BSG films. Therefore, three major sections of $\mathrm{B}_{2} \mathrm{H}_{6}: \mathrm{H}_{2}$ flux range are identified and referred to hereinafter as regime I $(400-650 \mathrm{sccm})$, II $(650-770 \mathrm{sccm})$ and III $(770-1000 \mathrm{sccm})$. A detailed description of the differences in regimes $\mathrm{I}$-III is provided in the following sections. 


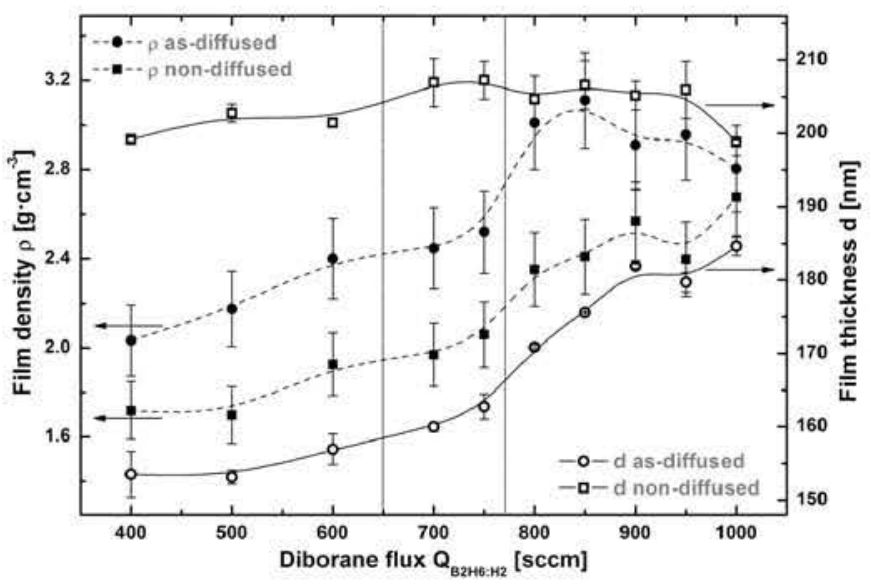

Figure 2. Film density $\rho$ (filled symbols, dashed guide-to-the-eye, left axis) and film thickness $\mathrm{d}$ (open symbols, straight guide-to-the-eye, right axis) in dependency on $\mathrm{B}_{2} \mathrm{H}_{6}: \mathrm{H}_{2}$ flux $\mathrm{Q}_{\mathrm{B} 2 \mathrm{H} 6: \mathrm{H} 2}$ for as-diffused (circles) and non-diffused samples (squares).

Film properties.-Film density $\rho$ (Fig. 2 , dashed lines, filled symbols) and thickness d (Fig. 2, solid lines, open symbols) are two important characteristics of BSG layers to determine the influence and subsequent change in molecular structure by variation of deposition or diffusion step parameters. Glass based doping sources are usually in a film thickness range of 10 to a few hundred nanometers depending on deposition technique and material. ${ }^{39}$ In case of CV-deposited BSG by the ICP-PECVD tool used in this experiment, the thickness is tuned by variation of deposition parameters depending on desired emitter, optical, and processing properties. As can be seen in Fig. 2, the $\mathrm{B}_{2} \mathrm{H}_{6}: \mathrm{H}_{2}$ flux is one such parameter to vary the film thickness $\mathrm{d}$ (right axis) and film density $\rho$ (left axis) in a wide range.

In the non-diffused state (squares in Fig. 2), the film thickness of the BSG layers is around $205 \mathrm{~nm}$ within the range of uncertainty for all investigated $\mathrm{B}_{2} \mathrm{H}_{6}: \mathrm{H}_{2}$ flux values. Considering the high dilution of $\mathrm{B}_{2} \mathrm{H}_{6}$ in $\mathrm{H}_{2}$ and knowing $\mathrm{H}_{2}$ to be an etchant, one would assume the effect of a decrease in thickness due to a higher etch rate with increasing $\mathrm{B}_{2} \mathrm{H}_{6}: \mathrm{H}_{2}$ flux. Yet in contrast to other techniques, i.e., direct plasma from parallel plate reactors, ICP-PECVD reactors show no such influence due to the distance between plasma and substrate and non-directional deposition method lacking a directing electric field (remote-like technique). ${ }^{22-26}$ However, the film density and thereby the molecular bond structure of the non-diffused dielectric layers show a distinctive change with an increase in $\mathrm{B}_{2} \mathrm{H}_{6}: \mathrm{H}_{2}$ flux for ICPPECVD tools. The density increases steadily during regime I + II, with a further increase in density growth rate in regime III showing indirectly the molecular changes of the BSG during transition from regime II to III.

The drive-in of the B dopants is carried out in a high-T step at around $930^{\circ} \mathrm{C}$ in nitrogen atmosphere in a standard tube diffusion furnace (cf. Experimental section). These as-diffused samples (circles in Fig. 2) show a thickness increase from 150 to $185 \mathrm{~nm}$ and a density increase of 2.0 to $2.9 \mathrm{~g} \cdot \mathrm{cm}^{-3}$ at maximum during an increase in $\mathrm{B}_{2} \mathrm{H}_{6}: \mathrm{H}_{2}$ flux from 400 to $1000 \mathrm{sccm}$. The lower overall values of film thickness compared to the as-deposited/non-diffused state are due to the increase in film density during high-T treatment and outdiffusion of B from the BSG layer into the substrate (i.e., emitter and in some cases BRL formation) and/or the furnace atmosphere. The density after the diffusion step follows a characteristic curve through all three regimes I-III. After a moderate increase up to $2.4 \mathrm{~g} \cdot \mathrm{cm}^{-3}$ at around $750 \mathrm{sccm}$, the film density curve drastically increases in regime III above $2.85 \mathrm{~g} \cdot \mathrm{cm}^{-3}$ and stagnates in the end at $2.8 \mathrm{~g} \cdot \mathrm{cm}^{-3}$. The increase in density is mirrored by an apparent increase in 'film growth rate' denoted by the simultaneous increase in film thickness in regime III.

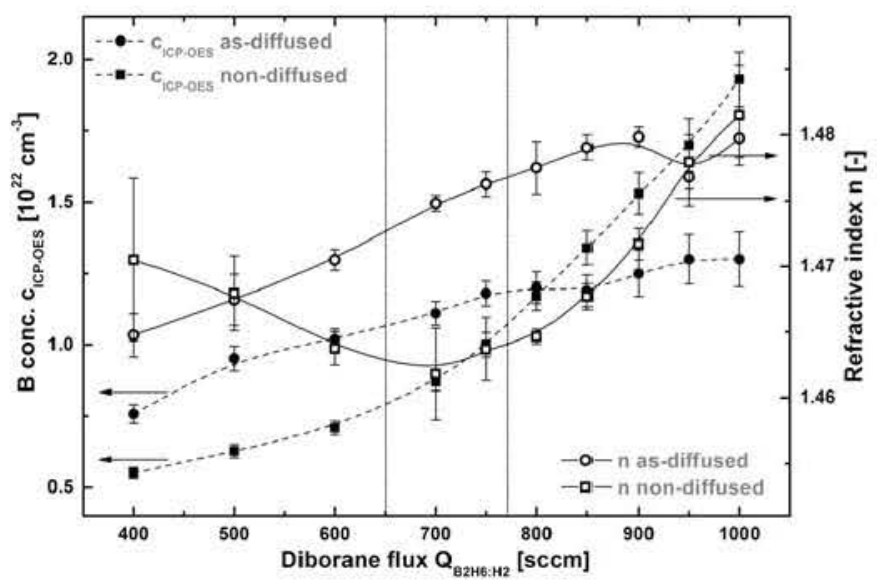

Figure 3. B concentration $\mathrm{C}_{\mathrm{ICP}-\mathrm{OES}}$ (filled symbols, dashed guide-to-the-eye, left axis) and refractive index $\mathbf{n}$ (open symbols, straight guide-to-the-eye, right axis) in dependency on $\mathrm{B}_{2} \mathrm{H}_{6}: \mathrm{H}_{2}$ flux $\mathrm{Q}_{\mathrm{B} 2 \mathrm{H} 6: \mathrm{H}_{2}}$ for as-diffused (circles) and non-diffused samples (squares).

In conclusion, the BSG densifies and its molecular structure is rearranged during the high-T step, while the emitter is diffused into the substrate. Furthermore, the molecular bond structure changes from films with the same thickness, but different densities, before high temperature treatment to films with a higher overall density and lower overall thickness.

Refractive index and B concentration.-Direct quantitative B concentration measurements of thin dielectric films were carried out in an indirect way using FTIR. Many common direct techniques similarly suited are complex and/or require a long preparation/measuring time. Those methods include SIMS or ICP/GD-OES/MS measurements. ${ }^{29}$ Nevertheless, to calibrate FTIR measurements, one of these techniques has to be used once. In this experiment, ICP-OES was used to calibrate the total B concentration (Fig. 3, dashed lines, filled symbols) in the BSG deposited by ICP-PECVD and measured by FTIR. The choice for ICP-OES is advantageous with respect to calibrated measurements of the total $\mathrm{B}$ concentration in dielectrics. Compared to incremental methods, ICP-OES measures larger volumes for higher accuracy in determining total B concentrations of glasses and directly uses calibration standards for every samples measurement cycle. To achieve an accurate value with ICP-OES, B needs to form a detectable complex with the HF, used to etch the BSG from the sample, after an incubation period. ${ }^{29}$ Therefore, any signal from cross-contamination due to machine components coming in direct contact with the HF has to be avoided/subtracted. A way to reduce the susceptibility to errors for comparable sample measurements is to determine the B concentration indirectly by FTIR. Once calibrated, FTIR yields the same information of absolute $\mathrm{B}$ concentration values.

The determined B concentration CICP-OES of non-diffused BSG layers (Fig. 3, filled squares) by ICP-OES measurements shows nearly linear increases in regime I and III, with a gradual increase of the slope during regime II. As will be seen later, this is due to a change in primary B molecular bond type from regime $\mathrm{I}$ to $\mathrm{III}$. The refractive index n (Fig. 3, solid lines, open symbols) for non-diffused films (open squares) follows in regime III the slope of the $\mathrm{B}$ concentration with a coefficient of $1.0(2) \cdot 10^{22} \mathrm{~cm}^{-3}$. In regime I, the refractive index curve declines in contrast to the $\mathrm{B}$ concentration due to the higher influence of the silicon oxide on optical properties rather than the lower incorporated B concentration.

As-diffused samples show an unexpected increase in B concentration for lower $\mathrm{B}_{2} \mathrm{H}_{6}: \mathrm{H}_{2}$ fluxes (regime I + II) after the high- $\mathrm{T}$ step. Yet considering the decrease in film thickness and the molecular bond density distribution among $\mathrm{B}$ bond types (see following sections), the increase in absolute B concentration in the as-diffused film can be explained. Although B is out-diffused from the film into the substrate 


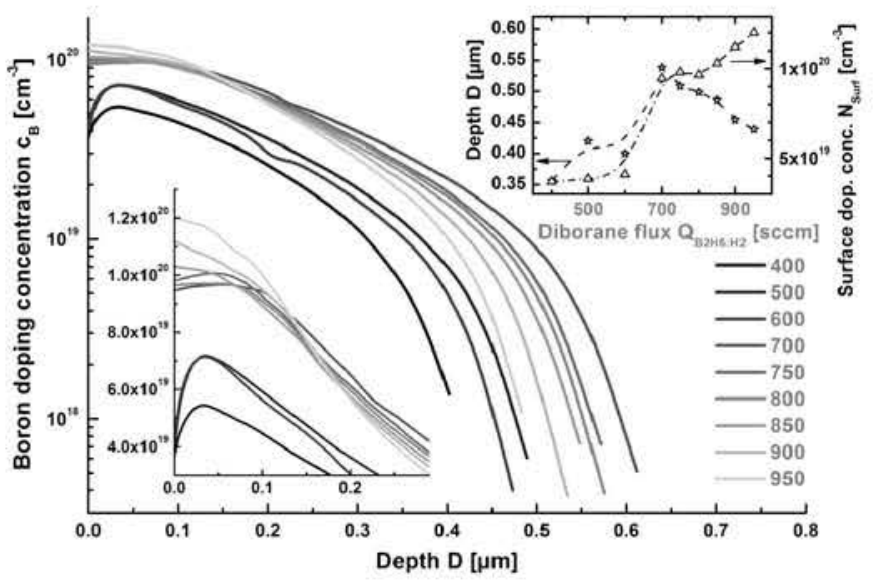

Figure 4. B doping concentration $\mathrm{c}_{\mathrm{B}}$ profile of emitters diffused from BSG layers deposited with increased $\mathrm{B}_{2} \mathrm{H}_{6}$ flux $\mathrm{Q}_{\mathrm{B} 2 \mathrm{H} 6: \mathrm{H} 2}$ (brightening grayscale) into crystalline Si substrate. Enlarged near surface doping concentration in lower left inset. Depth D (stars, left axis) and surface doping concentration $\mathrm{N}_{\text {Surf }}$ (triangles, right axis) in dependency on $\mathrm{B}_{2} \mathrm{H}_{6}: \mathrm{H}_{2}$ flux $\mathrm{Q}_{\mathrm{B} 2 \mathrm{H} 6: \mathrm{H}_{2}}$ in upper right inset.

as an emitter/BRL and out-diffused into the furnace atmosphere, the increased density of the film still allows more B atoms to form bonds with $\mathrm{Si}$ and $\mathrm{O}$ and thereby creating the seemingly paradox of an increase in B concentration after high-T step. The course of the curve, especially the jump before regime III, even results in a stagnation of B concentration with increasing $\mathrm{B}_{2} \mathrm{H}_{6}: \mathrm{H}_{2}$ flux after the high-T step. This only partially explains the stagnation of $\mathrm{B}$ concentration in regime III as will be seen in one of the following graphs.

The refractive index follows the $\mathrm{B}$ concentration curve of asdiffused samples in the full range of $\mathrm{B}_{2} \mathrm{H}_{6}: \mathrm{H}_{2}$ flux as well. Again, the reason is the reorganization of molecular bond types to a dielectric layer with a homogeneous molecular bond density distribution proportional to the film B concentration. Considering the sufficiently long diffusion step duration to reach an equilibrium state, this is to be expected. In conclusion, the refractive index is above the stoichiometric value of 1.45 for $\mathrm{SiO}_{2}{ }^{40}$ due to incorporated $\mathrm{B}$.

Emitter formation.-BSG layers are multi-functional. In one case these layers serve as a doping source. If the doped Si layer is p-type in an n-type crystalline Si substrate, as we investigate here, it is denoted as an emitter layer. Since in B emitters generally almost all dopant atoms are active, i.e., are substitutionally incorporated in the Si lattice due to the substitutional nature of diffusion, ${ }^{41}$ the absolute amount of diffused B (diffused B doping profile) can be fully characterized by ECV measurement. Fig. 4 shows typically shaped $B$ profiles from the series of $\mathrm{B}_{2} \mathrm{H}_{6}: \mathrm{H}_{2}$ fluxes (400-1000 sccm). The range of emitter sheet resistance $R_{\text {Sheet }}$ varies between 40 and $100 \Omega / \square$, while the emitter depth D lies in between 0.4 to $0.6 \mu \mathrm{m}$, respectively. In this case, the observed depth variations are not depending on temperature or duration, since the diffusion step parameters were the same for all samples, but are only dependent on the BSG properties. The depth solely depends on the $\mathrm{B}_{2} \mathrm{H}_{6}: \mathrm{H}_{2}$ flux $\mathrm{Q}_{\mathrm{B} 2 \mathrm{H} 6: \mathrm{H} 2}$ during deposition and the resulting type of diffusion source or rather the molecular bond structure of the layer, as well as the diffusion mechanism in the BSG and at the BSG/ $\mathrm{Si}$ substrate interface. The emitter depth increases with $\mathrm{B}_{2} \mathrm{H}_{6}: \mathrm{H}_{2}$ flux until the trend is reversed at a flux of about $700 \mathrm{sccm}$ to decrease again. This behavior is also mirrored in the sheet resistance values to be seen in Fig. 5 (dashed lines, filled symbols).

The surface doping concentration $\mathrm{N}_{\text {Surf }}$, considered to have influence on contact formation by metallization, ${ }^{19,20,42}$ is separately shown in the lower left inset in Fig. 4. Standard $\mathrm{B}$ diffusions from $\mathrm{BBr}_{3}$ sources allow mainly for emitter profiles with dopant depletion region on the surface, due to the necessity to completely remove the BRL (commonly done by oxidation at the end of the diffusion step) and

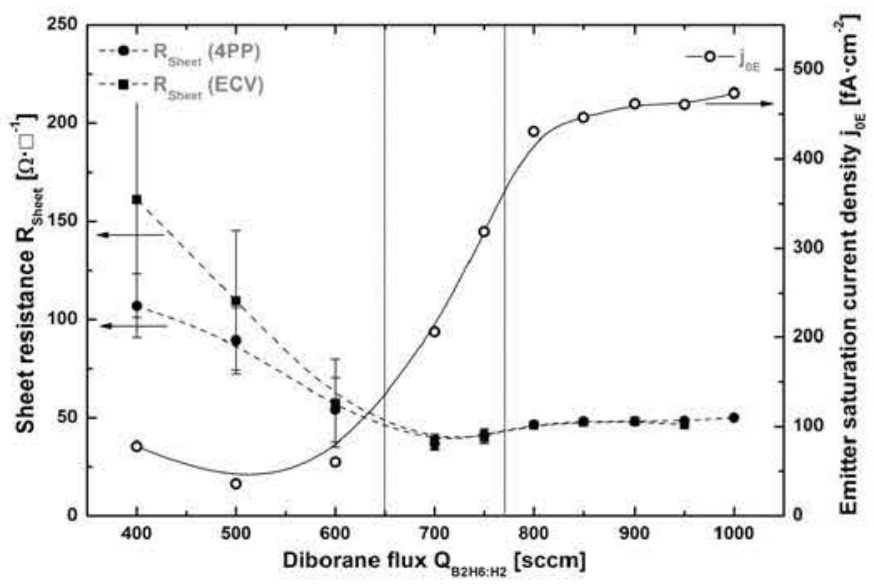

Figure 5. Sheet resistance $\mathrm{R}_{\text {Sheet }}$ (filled symbols, dashed guide-to-the-eye, left axis) and emitter saturation current density joE (open symbols, straight guide-to-the-eye, right axis) in dependency on $\mathrm{B}_{2} \mathrm{H}_{6}: \mathrm{H}_{2}$ flux $\mathrm{Q}_{\mathrm{B} 2 \mathrm{H} 6: \mathrm{H} 2}$. R $\mathrm{R}_{\text {Sheet }}$ is determined independently by four-point probe (4PP, circles) and electrochemical capacitance voltage (ECV, squares) measurement.

thus to achieve a sufficiently low recombination activity. Thereby a dopant depletion region at the surface is formed due to the re-diffusion of B atoms from the crystalline $\mathrm{Si}$ into the newly formed B containing silicon oxide layer caused by the higher affinity (solubility level) of $\mathrm{B}$ in the silicon oxide layer (pile-down effect). At around $930^{\circ} \mathrm{C}$ the solubility level for B in Si ranges from $8.5(5) \cdot 10^{19} \mathrm{~cm}^{-343}$ up to $1.15(5) \cdot 10^{20} \mathrm{~cm}^{-341,44}$ depending on measurement technique. The maximum solubility of $\mathrm{B}$ in $\mathrm{SiO}_{2}$ at $930^{\circ} \mathrm{C}$ is $>2 \cdot 10^{20} \mathrm{~cm}^{-345}$ as commonly derived from the experimentally accessible, low segregation coefficient of $\approx 0.3$ for B. ${ }^{46}$ Applying a CVD-BSG as dopant source causes a similar depletion effect, if the B concentration in the CVDBSG is too low to generate a B concentration at the $\mathrm{Si}$ surface as high as the solubility limit of B in Si. This depletion in B concentration at the surface can be seen in the emitter profiles of CVD BSG layers deposited with $\mathrm{B}_{2} \mathrm{H}_{6}: \mathrm{H}_{2}$ fluxes below $600 \mathrm{sccm}$. Two factors influence the B depletion at the Si surface: Firstly, B can diffuse back into the oxide, if the change in solubility limit with declining temperature in the cooling phase after the high-T step permits it. This effect is similar to the $\mathrm{BBr}_{3}$ case. Secondly, the $\mathrm{B}$ in the Si bulk can diffuse deeper into the $\mathrm{Si}$ substrate. Thereby, the surface is depleted of $\mathrm{B}$, while due to the segregation coefficient the B flux from the BSG into the $\mathrm{Si}$ declines below the minimum flux necessary to maintain the high (non-depleted) surface concentration. This process lasts for as long as the maximum temperature of the diffusion step is maintained. Although highly dependent on diffusion step and deposition parameters, the second effect is typical for CVD BSG films and is advantageous to prevent a BRL formation at the Si surface. BRLs are typically formed in case of CVD BSG layers deposited with $>700 \mathrm{sccm} \mathrm{B} \mathrm{B}_{2} \mathrm{H}_{6}: \mathrm{H}_{2}$ flux. A typical increase of doping concentration above the solubility limit in the first $50-100 \mathrm{~nm}$ of the $\mathrm{Si}$ wafer is evident in these cases $\mathrm{s}^{2,30,31}$ and reason for an increase in recombination activity ${ }^{30}$ as well as a reduced diffusion depth due to a decreased diffusion coefficient $t^{32,33}$ in the BRL between BSG and Si substrate. Therefore, a cross-over point of doping depth profiles with increasing $\mathrm{B}_{2} \mathrm{H}_{6}: \mathrm{H}_{2}$ flux is visible at around $170 \mathrm{~nm}$ depth for profiles of regime II \& III. Surface depleted profiles from regime I show no such behavior due to the finite nature of the BSG as a dopant source. The ensuing change in surface concentration increase of the profiles shows the rapid change of dopant source type from finite to infinite within a range of only $100 \mathrm{sccm}$ difference in $\mathrm{B}_{2} \mathrm{H}_{6}: \mathrm{H}_{2}$ flux $\mathrm{Q}_{\mathrm{B} 2 \mathrm{H} 6: \mathrm{H} 2}$ from 600 to $700 \mathrm{sccm}$. This marks the change from depleted surface to BRL formation. For better comparison, in particular to depict the cross-over point marking the formation of a BRL, the upper right inset in Fig. 4 shows the profile depth D (left inset axis, star symbols) and the B doping concentration at the surface $\mathrm{N}_{\text {surf }}$ (right inset axis, triangular symbols) in dependence on the 
$\mathrm{B}_{2} \mathrm{H}_{6}: \mathrm{H}_{2}$ flux. The first increase of the slope of depth D at around $650 \mathrm{sccm}$ marks the lowest concentration for BRL formation at the transition from regime I to II. With further increase in BRL thickness and density at a diborane flux of around $750 \mathrm{sccm}$, i.e., regime III, the depth of the profile - despite constant diffusion step duration and higher B concentration in the BSG - drops linearly with increasing $\mathrm{N}_{\text {surf }}$ resp. Q $\mathrm{Q}_{\mathrm{B} 2 \mathrm{H} 6: \mathrm{H} 2}$ :

$$
\mathrm{D}[\mu m]=-3.8(3) \cdot 10^{-4} \cdot \mathrm{Q}_{\mathrm{B} 2 \mathrm{H} 6 \mathrm{H} 2}[\mathrm{sccm}]+0.80(3)
$$

Considering the dependence of the emitter profiles on the $\mathrm{B}_{2} \mathrm{H}_{6}: \mathrm{H}_{2}$ flux, the overall course of the sheet resistance curve determined from $4 \mathrm{PP}$ as well as ECV measurements for increasing $\mathrm{B}_{2} \mathrm{H}_{6}: \mathrm{H}_{2}$ flux is as predicted for both measurement techniques (Fig. 5). In regime I, the resistance value drops linearly with a slight offset between both techniques due to a higher uncertainty for ECV measurements for lower doped layers. ${ }^{47}$ In regime II, the sheet resistance reaches its minimum to asymptotically increase in regime III to just below $50 \Omega / \square$. The slight increase in this regime can be explained by the insufficient further increase in surface concentration forming a BRL compensating the decrease in emitter depth. In case of gas phase diffusions (e.g., $\mathrm{BBr}_{3}$ ), BSG layers with such high $\mathrm{B}$ concentrations and no significant indiffusion of $\mathrm{B}$ during BSG growth at high- $\mathrm{T}$ are impossible to realize ${ }^{41}$ making the here depicted behavior of emitter formation by oversaturated BSG layers unique to pre-deposited diffusion sources, such as CVD layers. Aside from the difference in growth of the BSG into or on the Si substrate, as found for gas phase formed and CVD deposited BSG layers, respectively, the ambient temperature during BSG growth is the main factor for the difference in film growth, molecular film composition and diffusion source behavior.

A means to quantitatively evaluate the recombination activity of the emitter is to passivate the surface as perfectly as possible (i.e., $\mathrm{Al}_{2} \mathrm{O}_{3}$ for p-type emitter), use lowly doped substrates (i.e., $200 \Omega \mathrm{cm}$ n-type FZ-Si) for low base recombination and symmetrically diffused samples to measure the emitter saturation current density joE. ${ }^{36}$ The recombination due to the highly doped regions and the overall doping of the emitter influences this specific value. Therefore, emitter saturation current density $j_{O E}$ continuously increases throughout the increasing $\mathrm{B}_{2} \mathrm{H}_{6}: \mathrm{H}_{2}$ flux range (Fig. 5). The major increase can be observed in regime II during the rapid increase of surface and overall doping concentration. In regime III, the BRL formation has less influence on an already high joe value of above $400 \mathrm{fA} / \mathrm{cm}^{2}$. Optimal lowest values are to be reached in a narrow window around $500 \mathrm{sccm} \mathrm{B}_{2} \mathrm{H}_{6}: \mathrm{H}_{2}$ flux, again considering the specific deposition and diffusion step parameter set. The overall behavior is to be expected for a broad range of parameters, yet the optimal range is specific to the individual parameter set. Furthermore, the CVD technique of ICP aids to reach relatively low $\mathrm{j}_{\mathrm{OE}}$ values of below $35 \mathrm{fA} / \mathrm{cm}^{2}$ due to lower ion bombardment and film stress management during BSG deposition. ${ }^{22,23}$

The question arises how the final B concentration in the BSG film in the non- and as-diffused samples is correlated to the B concentration in the gas phase during deposition. Since all deposition durations are identical and the growth of the BSG film bulk is considered constant over time, a direct comparison of the B concentration is possible.

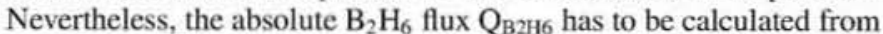
the $\mathrm{H}_{2}$ diluted $\mathrm{B}_{2} \mathrm{H}_{6}: \mathrm{H}_{2}$ flux $\mathrm{Q}_{\mathrm{B} 2 \mathrm{H} 6: \mathrm{H} 2}$ depending on the relative $\mathrm{B}_{2} \mathrm{H}_{6}$ concentration $\mathrm{c}_{\% \mathrm{~B} 2 \mathrm{H} 6}$ by

$$
\mathrm{Q}_{\mathrm{B} 2 \mathrm{H} 6}=\frac{\mathrm{c}_{\tilde{\kappa} . \mathrm{B} 2 \mathrm{H} 6}}{100} \cdot \mathrm{Q}_{\mathrm{B} 2 \mathrm{H} 6 \mathrm{H} 2}
$$

The $\mathrm{B}_{2} \mathrm{H}_{6}$ gas flux weighted content $\mathrm{ct}_{\mathrm{g}}$ can be calculated from $\mathrm{Q}_{\mathrm{B} 2 \mathrm{H} 6}$ as follows:

$$
\mathrm{ct}_{\mathrm{g}}=\frac{1}{1+\frac{\mathrm{Q}_{\mathrm{S} 1 \mathrm{H} 4}}{\mathrm{Q}_{\mathrm{B} 2 \mathrm{H} 6}}}
$$

Further weighting by the atomic mass of $\mathrm{B}$ and $\mathrm{Si}$ leads to $\mathrm{ct}_{\mathrm{g} . \mathrm{m}}$

$$
\mathrm{ct}_{\mathrm{g} \cdot \mathrm{m}}=\frac{\mathrm{ct}_{\mathrm{g}}}{1+\frac{\mathrm{m}_{\mathrm{a} i \mathrm{i}}}{\mathrm{m}_{\mathrm{a} \cdot \mathrm{B}}}}
$$

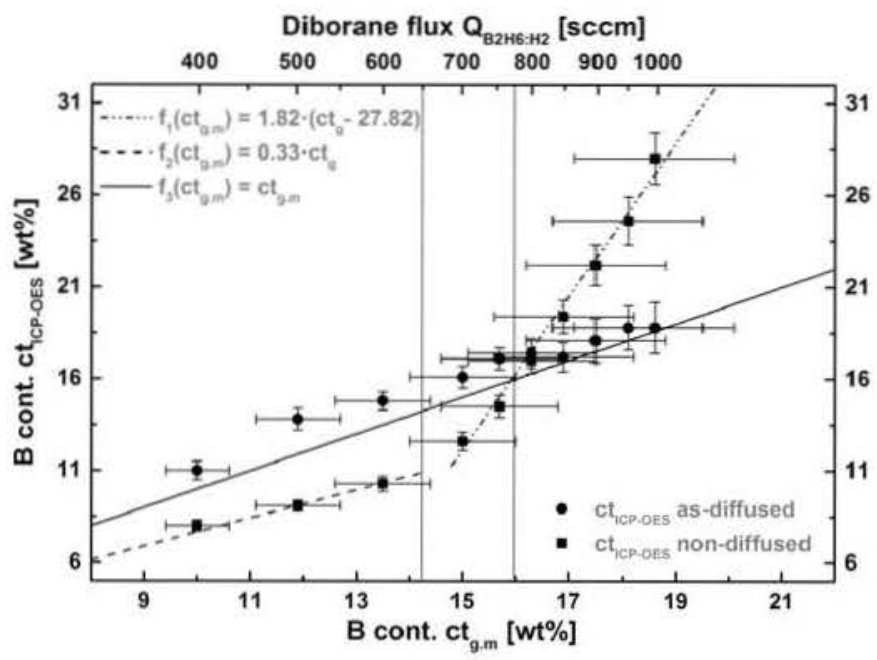

Figure 6. B content $\mathrm{ct}_{\mathrm{ICP}-\mathrm{OES}}$ for non- and as-diffused samples in dependency on the $\mathrm{B}$ content $\mathrm{ct}_{\mathrm{gm}}$ (gas flux and atomic mass normalized) including fits $f_{1}\left(c_{g, m}\right)$ and $f_{2}\left(c t_{g, m}\right)$ to the measured data points. $f_{3}\left(c_{g, m}\right)$ is the identity function. Included are the formula for CtICP-OES (see Eq. 5) dependent on

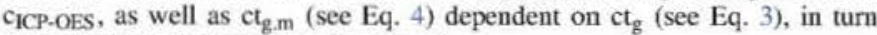
dependent on absolute $\mathrm{B}_{2} \mathrm{H}_{6}: \mathrm{H}_{2}$ flux $\mathrm{Q}_{\mathrm{B} 2 \mathrm{H} 6}$.

The B content $\mathrm{Ct}_{\mathrm{ICP}-\mathrm{OES}}$ was derived from the B concentration cICP-OES as follows:

$$
\begin{aligned}
\mathrm{Ct}_{\mathrm{ICP}-\mathrm{OES}} & =\frac{\mathrm{c}_{\mathrm{ICP}-\mathrm{OES}}}{\rho_{a t}}=\frac{\mathrm{c}_{\mathrm{ICP}-\mathrm{OES}}}{3 \cdot \rho_{m o l}} \\
& =\frac{\mathrm{c}_{\mathrm{ICP}-\mathrm{OES}} \cdot M_{S i O x: B}}{3 \cdot \rho \cdot \mathrm{N}_{A}} \cong \frac{\mathrm{c}_{\mathrm{ICP}-\mathrm{OES}} \cdot M_{S i O 2}}{3 \cdot \rho \cdot \mathrm{N}_{A}}
\end{aligned}
$$

For approximation purposes, the molar mass of Si dioxide $\mathrm{M}_{\mathrm{SiO} 2}$ with $60.08(1) \mathrm{g} \cdot \mathrm{mol}^{-1}$ was used for $\mathrm{M}_{\mathrm{SiO}: \mathrm{B}}$.

Fig. 6 shows the dependence of the ICP-OES measured B content $\mathrm{et}_{\text {ICP-OES }}$ in the BSG film on $\mathrm{ct}_{\mathrm{g} . \mathrm{m}}$. Fitted to the measured data points are two linear curves $\mathrm{f}_{1}\left(\mathrm{ct}_{\mathrm{g} . \mathrm{m}}\right)$ (dotted/dashed line) to $\mathrm{f}_{2}\left(\mathrm{ct}_{\mathrm{g} . \mathrm{m}}\right)$ (dashed line) for the non-diffused samples. The two linear functions differ by a large change in slope of $\mathrm{f}_{2}\left(\mathrm{ct}_{\mathrm{g}, \mathrm{m}}\right)$ from 0.33 in regime $\mathrm{I}$ to around 1.82 of $\mathrm{f}_{\mathrm{l}}\left(\mathrm{ct}_{\mathrm{g} . \mathrm{m}}\right)$ in regime II + III. Explainable by an increased incorporation of B in the BSG film, this slope change can be attributed to a difference in film growth mechanism beyond a certain amount of incorporated B in the molecular bond structure and density as described in the following sections of FTIR measurements. In contrast, the asdiffused samples' data points of ctICP-OES closely follow the identity function $\mathrm{f}_{3}\left(\mathrm{ct}_{\mathrm{g} . \mathrm{m}}\right)$ (solid line, non-fitted curve). The temperature treatment of the as-diffused samples is therefore considered to change the molecular bonding structure of the BSG film in all three regimes from the unstable non-diffused state to a homogeneous molecular bond structure after diffusion step. Hereby, the film thickness decrease in

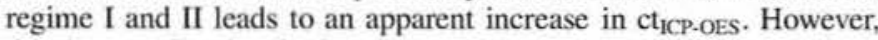
the change of molecular bond type during heat-treatment seem to allow for less variation in $\mathrm{Si}-\mathrm{B}-\mathrm{O}$ or $\mathrm{Si}-\mathrm{B}-\mathrm{H}$ bonds in the BSG film, thus reducing the number of different bonds by rearrangement of $B$ incorporated in the amorphous structure of the BSG. The measured B content $\mathrm{ct}_{\text {ICP-OES }}$ after heat-treatment is reduced compared to the BSG films before the diffusion step. Thereby, the intercept point lies near the change from regime II to III. Considering the randomly chosen diffusion temperature and the dependency of as-diffused film properties thereof, it is not clear without further experiments if this is only a coincidence. It can be argued that the ct ICP-OES values in regime III, following the identity function of the expected B content $\mathrm{ct}_{\mathrm{g} . \mathrm{m}}$ in the BSG, are independent in a certain stable diffusion parameter window, e.g., as a non-finite doping source or even considered to be consisting of fixed $\mathrm{B}$ bonds. The latter meaning that a pre-diffusion determined amount of B bonds of not available/capable B atoms for solid-state diffusion exists, i.e., $\mathrm{B}$ incorporated in the (Si-)B-O bond with an 


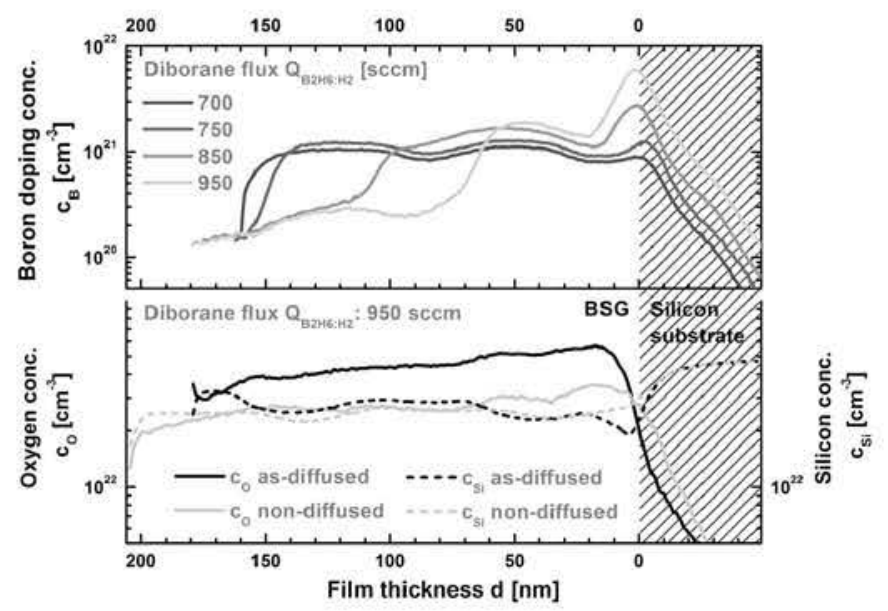

Figure 7. $\mathrm{B}$ doping concentration $\mathrm{c}_{\mathrm{B}}$ in upper graph for different absolute $\mathrm{B}_{2} \mathrm{H}_{6}: \mathrm{H}_{2}$ flux $\mathrm{Q}_{\mathrm{B} 2 \mathrm{H}_{6}}$ values of as-diffused samples. $\mathrm{O}$ (solid lines) and $\mathrm{Si}$ (dashed lines) concentration profiles in lower graph for a $\mathrm{B}_{2} \mathrm{H}_{6}: \mathrm{H}_{2}$ flux of 950 sccm of as- (black lines) and non-diffused (gray lines) samples. All graphs dependent on BSG film thickness $\mathrm{d}$. Silicon substrate depicted as shaded area on the right hand part of both graphs.

FTIR peak wavenumber around $1395 \mathrm{~cm}^{-1}$. Most of the B stemming from the difference in B content from non- and as-diffused films in regime III is not lost to the furnace atmosphere, but rather clustered in the forming BRL, showing further proof for the strong BRL formation above $770 \mathrm{sccm}$ at the chosen drive-in conditions.

GD-OES allows for measuring depth profiles similar to ECV technique, yet by Ar plasma etching instead of chemical etching of the Si substrate. Calibration of concentration values can be done by measurement of standards or in this case, by ICP-OES calibration. Depth calibration can be done by ellipsometry measurement for the BSG layer. Qualitative and quantitative information can be derived from these profiles, as to how the $\mathrm{B}$ doping profile changes in accordance with $\mathrm{O}$ and $\mathrm{Si}$ concentration, high-T step temperature and $\mathrm{B}_{2} \mathrm{H}_{6}: \mathrm{H}_{2}$ flux. Fig. 7 depicts in the lower graph $\mathrm{Si}$ (dashed lines) and $\mathrm{O}$ (solid lines) concentration profiles for a fixed $\mathrm{B}_{2} \mathrm{H}_{6}: \mathrm{H}_{2}$ flux of $950 \mathrm{sccm}$. The interface between BSG (left part of graph) and $\mathrm{Si}$ substrate (shaded part on the right) coincides with the crossing of the $\mathrm{O}$ and $\mathrm{Si}$ profile lines. The change in the BSG layer from non- (gray) to as-diffused (black) state during high-T step results in a drop of $\mathrm{Si}$ concentration at the interface. Substitutional O and B atoms accumulate in the forming layer. While B diffuses further into the Si substrate (light gray as-diffused profile in upper graph), O largely remains in the BSG layer. Since BRL formation depends on the overall B content in the non-diffused layer, as mentioned before, an increase in $\mathrm{B}$ content near the interface of BSG an $\mathrm{Si}$ substrate with increasing $\mathrm{B}_{2} \mathrm{H}_{6}: \mathrm{H}_{2}$ flux is to be expected in case of BRL formation. Besides this accumulation of $B$ near the interface with increasing $\mathrm{B}_{2} \mathrm{H}_{6}: \mathrm{H}_{2}$ flux, an increased diffusion from the surface of the BSG layer (i.e., far from the interface) toward the interface can be seen. A plateau of B concentration of around $2 \cdot 10^{20} \mathrm{~cm}^{-3}$ grows from the surface of the BSG layer into the upper plateau of around $1 \cdot 10^{21} \mathrm{~cm}^{-3}$ with increasing $\mathrm{B}_{2} \mathrm{H}_{6}: \mathrm{H}_{2}$ flux. This increased diffusion of $\mathrm{B}$ from the surface to the interface for higher $\mathrm{B}_{2} \mathrm{H}_{6}: \mathrm{H}_{2}$ fluxes, but at fixed diffusion temperature, supports the theory of enhanced $\mathrm{B}$ diffusion due to $\mathrm{O} .^{32,33}$ Before the high- $\mathrm{T}$ step all profiles of the non-diffused samples resemble the as-diffused profile for $700 \mathrm{sccm}$. The plateau height is depending on the $\mathrm{B}_{2} \mathrm{H}_{6}: \mathrm{H}_{2}$ flux during deposition, but is otherwise homogenous throughout the depth of the BSG film. The change during high-T treatment and the accumulation of $B$ atoms at the interface can only be seen for $\mathrm{B}_{2} \mathrm{H}_{6}: \mathrm{H}_{2}$ fluxes above $750 \mathrm{sccm}$. Therefore, the peak of $\mathrm{B}$ concentration, the drop of $\mathrm{Si}$ concentration and the increase in $\mathrm{O}$ atoms near the interface is indicative of BRL formation for layers deposited with a $\mathrm{B}_{2} \mathrm{H}_{6}: \mathrm{H}_{2}$ flux above $750 \mathrm{sccm}$, as mentioned before.

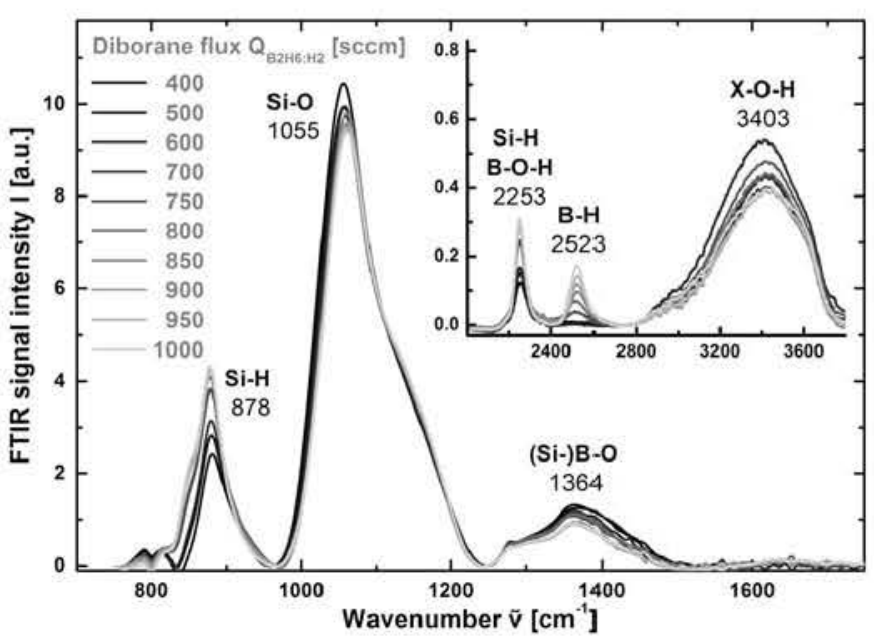

Figure 8. FTIR signal intensity I (absorbance) of non-diffused BSG layers in dependency on wavenumber $\tilde{v}$ deposited with increased $\mathrm{B}_{2} \mathrm{H}_{6}: \mathrm{H}_{2}$ flux $\mathrm{Q}_{\mathrm{B} 2 \mathrm{H} 6: \mathrm{H} 2}$ (brightening grayscale) on crystalline Si substrates. Enlarged spectrum in the range of $2200-3800 \mathrm{~cm}^{-1}$ in upper right inset.

FTIR spectra.-FTIR spectra indicate the molecular bond types, bond density and bond distribution within the BSG layer. Typical molecular bonds in CVD BSG include $\mathrm{Si}-\mathrm{O}, \mathrm{B}-\mathrm{O}, \mathrm{Si}-\mathrm{B}-\mathrm{O}, \mathrm{Si}-\mathrm{H}, \mathrm{B}-\mathrm{H}$ and $\mathrm{Si}-\mathrm{Si}$. The evaluated spectrum is limited to a wavenumber range of $750-3800 \mathrm{~cm}^{-1}$, giving all the relevant information about the BSG as a diffusion source and optical layer without major influence of Si-O or $\mathrm{Si}-\mathrm{H}$ bonds at smaller wavenumbers.

FTIR spectra for non- and as-diffused samples are displayed in Figs. 8 and 9, respectively. They show the spectra of $\mathrm{a} \mathrm{SiO}_{\mathrm{x}}$ layer with additional $\mathrm{B}$ related peaks. Since the reaction gases include $\mathrm{SiH}_{4}, \mathrm{CO}_{2}$ and $\mathrm{B}_{2} \mathrm{H}_{6}: \mathrm{H}_{2}$, bonds including $\mathrm{C}$ or $\mathrm{H}$ could be expected. Former studies show a strongly reduced incorporation of $\mathrm{C}$ based bonds into the amorphous layer ${ }^{48}$ in comparison to, e.g., $\mathrm{N}$ based bonds from $\mathrm{N}_{2} \mathrm{O}^{49}$ as an oxidation source. The reason is the dissociation of $\mathrm{CO}_{2}$ in $\mathrm{CO}$ and $\mathrm{O},{ }^{50}$ whereby $\mathrm{CO}$ cannot be incorporated in the film. ${ }^{48}$ Therefore, only $\mathrm{H}$ bonds do appear in detectable concentrations in this part of the spectrum scaled by the increase in $\mathrm{B}_{2} \mathrm{H}_{6}: \mathrm{H}_{2}$ flux. Far more prominent is the central $\mathrm{O}-\mathrm{Si}-\mathrm{O}$ peak at $1055 \mathrm{~cm}^{-1}$ for non-diffused and $1084 \mathrm{~cm}^{-1}$ for as-diffused samples, respectively, from the symmetric Si-O stretching mode region ${ }^{51-55}$ (given are always mean peak center values over the whole $\mathrm{B}_{2} \mathrm{H}_{6}: \mathrm{H}_{2}$ flux range, cf. Table II). The

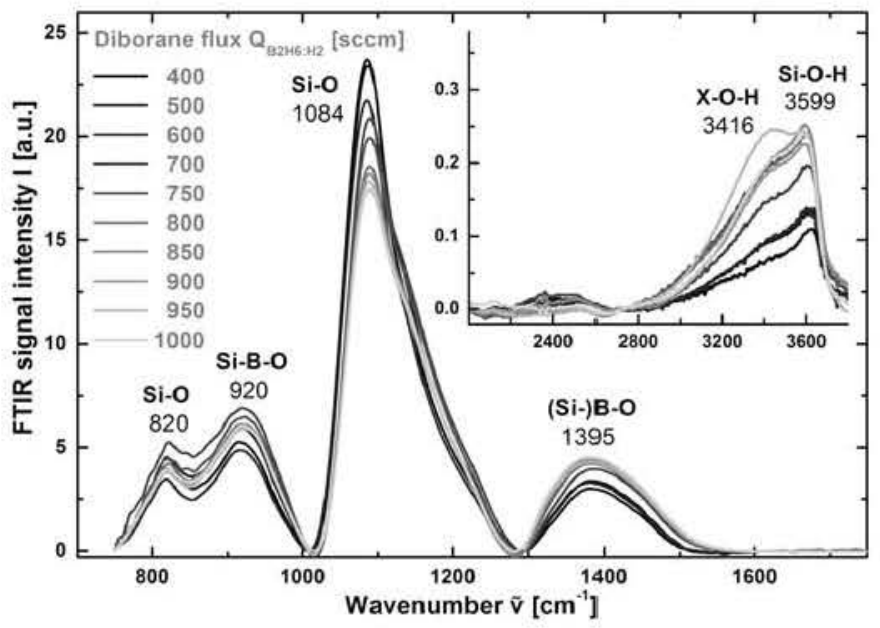

Figure 9. FTIR signal intensity I (absorbance) of as-diffused BSG layers in dependency on wavenumber $\tilde{v}$ deposited with increased $\mathrm{B}_{2} \mathrm{H}_{6}: \mathrm{H}_{2}$ flux $\mathrm{Q}_{\mathrm{B} 2 \mathrm{H} 6 \mathrm{H} 2}$ (brightening grayscale) on crystalline $\mathrm{Si}$ substrates. Enlarged spectrum in the range of $2200-3800 \mathrm{~cm}^{-1}$ in upper right inset. 


\begin{tabular}{|c|c|c|c|c|}
\hline Mean peak center & Peak intensity change & wavenumber shift & Type of bond & Reference \\
\hline \multicolumn{5}{|l|}{ Non-diffused } \\
\hline 878 & 7 & $\leftrightarrow$ & $\mathrm{Si}-\mathrm{H}$ & 55 \\
\hline 1055 & $\searrow$ & $\rightarrow$ & $\mathrm{O}-\mathrm{Si}-\mathrm{O}$ & $51-55$ \\
\hline 1180 & $\searrow$ & $\leftrightarrow$ & $\mathrm{O}-\mathrm{Si}-\mathrm{O}$ & $51-53$ \\
\hline 1364 & $\searrow$ & $\rightarrow$ & $\mathrm{B}-\mathrm{O} / \mathrm{Si}-\mathrm{B}-\mathrm{O}$ & $54-58$ \\
\hline 2253 & $\bar{\gamma}$ & $\leftrightarrow$ & Si-H B-O-H & $53,55,56$ \\
\hline 2523 & $\nearrow$ & $\leftrightarrow$ & B-H & 59,60 \\
\hline 3403 & $\searrow$ & $\rightarrow$ & $\mathrm{Si}-\mathrm{O}-\mathrm{H} \mathrm{H}-\mathrm{O}-\mathrm{H} / \mathrm{B}-\mathrm{O}-\mathrm{H}$ & $53,55,56,58$ \\
\hline \multicolumn{5}{|l|}{ As-diffused } \\
\hline 820 & & $\leftrightarrow$ & $\mathrm{Si}-\mathrm{O}$ & $53,56,57$ \\
\hline 920 & 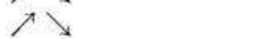 & $\leftrightarrow$ & Si-B-O & $55-58$ \\
\hline 1084 & $\searrow$ & $\rightarrow$ & $\mathrm{O}-\mathrm{Si}-\mathrm{O}$ & $51-55$ \\
\hline 1395 & $\lambda$ & $\leftarrow$ & $\mathrm{B}-\mathrm{O} / \mathrm{Si}-\mathrm{B}-\mathrm{O}$ & $54-58$ \\
\hline 3416 & $\nearrow$ & $\rightarrow$ & Si-O-H H-O-H / B-O-H & $53,55,56,58$ \\
\hline 3599 & $\nearrow$ & $\leftarrow$ & $\mathrm{Si}-\mathrm{O}-\mathrm{H}$ & $53,55,56,58$ \\
\hline
\end{tabular}

Si-O peak is slightly shifted to lower wavenumbers compared to pure, i.e., thermally grown $\mathrm{SiO}_{x}$ films (peak around $1070-1107 \mathrm{~cm}^{-1}$ ), and even slightly wider in peak width as common in borosilicate glasses. ${ }^{55}$ The $1180 \mathrm{~cm}^{-1}$ peak on the flank of the main $\mathrm{Si}-\mathrm{O}$ peak is assumed to be the asymmetric $\mathrm{Si}-\mathrm{O}$ stretching mode ${ }^{51-53}$ widening the main peak to higher wavenumbers. The assumption is based on the lack of a reliable correlation to the B content of the layer and the higher anticipated peak intensity of the $\mathrm{Si}-\mathrm{O}$ mode. All other peaks can be safely associated with the influence of the $\mathrm{B}_{2} \mathrm{H}_{6}: \mathrm{H}_{2}$ flux and are therefore part of the following discussion. Intensity change and wavenumber shift in dependency of $\mathrm{B}_{2} \mathrm{H}_{6}: \mathrm{H}_{2}$ flux change are listed in detail in Table II including molecular bond type.

Before the diffusion step, BSG layers show $\mathrm{Si}-\mathrm{H}$ bonds at 878 $\mathrm{cm}^{-155}$ and $2253 \mathrm{~cm}^{-153,55}$ for different vibrational modes. In case of the $2253 \mathrm{~cm}^{-1}$ peak a B-O-H bond ${ }^{56}$ is also possible, given the strong linear dependence on the $\mathrm{B}_{2} \mathrm{H}_{6}: \mathrm{H}_{2}$ flux. In any case, the increase of bond density is due to the increased flux of $\mathrm{H}$ and $\mathrm{B}$ from $\mathrm{B}_{2} \mathrm{H}_{6}: \mathrm{H}_{2}$ considering the constant flux of $\mathrm{SiH}_{4}$. The peak at $2253 \mathrm{~cm}^{-1}$ increases thereby in height and area, while the peak's center of gravity shifts only slightly to lower wavenumbers in regimes I \& II. This behavior of peak change stagnates in regime III. Therefore, this $\mathrm{Si}-\mathrm{H}$ or $\mathrm{B}-\mathrm{O}-\mathrm{H}$ bond is a stable indicator of the $\mathrm{B}$ concentration in the film given the proportional change in density with $\mathrm{B}_{2} \mathrm{H}_{6}: \mathrm{H}_{2}$ flux. It has to be noted that the rehydration after deposition of the commonly highly hygroscopic BSG layers forming the $\mathrm{B}-\mathrm{O}-\mathrm{H}$ bond is also linear with time and $\mathrm{B}$ content of the film, ${ }^{56}$ and therefore not influencing the former conclusion. Rather unexpectedly, the prominent (Si-)B-O bond of the stretching mode at $1364 \mathrm{~cm}^{-1}$ declines with increased $\mathrm{B}_{2} \mathrm{H}_{6}: \mathrm{H}_{2}$ flux compared to studies on BSG layers grown by different methods. ${ }^{54-58}$ The shift of the peaks' center of gravity to higher wavenumber values is also uncharacteristically. In comparison to asdiffused samples, both the intensity increases and the peak shifts to lower wavenumber values, as to be expected. Therefore, B atoms are to be presumed to form different bonds in the non-diffused layers due to the high availability of another element. $\mathrm{H}$ is suspected to be this bonding partner to $B$ instead. This can be seen by both the $2253 \mathrm{~cm}^{-1}$ peak as well as the B-H bond around $2523 \mathrm{~cm}^{-1} \cdot{ }^{59,60}$ Looking at the previously mentioned studies, B-H bonds rarely seem to form by these other deposition techniques. Whether this difference in B incorporation in form of B-H bonds instead of B-O bonds is characteristic for ICP-PECVD and/or due to the high amount of $\mathrm{H}$ in the plasma, is not clear at this point. B-H bonds can only form prior to the diffusion step considering their weak bonding energy as well as the availability of $\mathrm{H}$ solely in the plasma. In contrast, $\mathrm{B}-\mathrm{O}-\mathrm{H}$ bonds can form whenever the BSG layer is exposed to $\mathrm{H}_{2} \mathrm{O}$, e.g., in air. ${ }^{56}$
B content.-After the diffusion step the $\mathrm{B}$ bonds rearrange to form stable bonds less likely to be B-O-H bonds. ${ }^{56}$ Therefore, B-O-H peaks vanish after the diffusion step. Instead the common ( $\mathrm{Si}$-)B-O peak at around $1395 \mathrm{~cm}^{-154-58}$ becomes the major B bond type in the layer. The slight shift to higher wavenumbers stems probably from a change in layer strain common in diffused glass layers. ${ }^{61}$ Further change in molecular bonds after diffusion step can be seen in the interdependent $\mathrm{Si}-\mathrm{O}\left(820 \mathrm{~cm}^{-1}\right)^{53,56,57}$ and Si-B-O $\left(920 \mathrm{~cm}^{-1}\right)^{55-58}$ bonds. Both type of bonds' intensities rise and then stagnate again with an increase in $\mathrm{B}_{2} \mathrm{H}_{6}: \mathrm{H}_{2}$ flux. The intensity increase in regime $\mathrm{I}$ is maximized in regime II. The intensity value reaches a fixed value in regime III. If the course of the change of intensity of the peaks at 820 and $920 \mathrm{~cm}^{-1}$ in regime II and III is compared to the course of $\mathrm{j}_{\mathrm{OE}}, \mathrm{R}_{\text {Sheet }}, \mathrm{D}$ and $\mathrm{N}_{\text {Surf }}$ (cf. Figs. 3 and 4) at the same diborane flux $\mathrm{Q}_{\mathrm{B} 2 \mathrm{H} 6: \mathrm{H} 2}$ range, it is found to be similar. The explanation of this behavior is the formation of a BRL at the interface between BSG and bulk $\mathrm{Si}$, as discussed before. This layer forms for $\mathrm{B}_{2} \mathrm{H}_{6}: \mathrm{H}_{2}$ fluxes above $700 \mathrm{sccm}$, at the same flux value where both bonds reach their maximum bond density, indicated by their intensity. B is incorporated in the Si-B-O bond at $920 \mathrm{~cm}^{-1}$ and $\mathrm{O}$ shifted to the $\mathrm{Si}-\mathrm{O}$ bond at $820 \mathrm{~cm}^{-1}$ until the $\mathrm{B}$ diffusion is hindered by the BRL resulting in a change in bonding site for $\mathrm{B}$ atoms. Since the peak at $1395 \mathrm{~cm}^{-1}$ changes only marginally above a $\mathrm{B}_{2} \mathrm{H}_{6}: \mathrm{H}_{2}$ flux of $700 \mathrm{sccm}$ as well, $\mathrm{B}$ is suspected to cluster or form $\mathrm{Si}-\mathrm{B}$ bonds that form $\mathrm{B}-\mathrm{O}-\mathrm{H}$ bonds after rehydration. The broad peak band from 2900 to $3600 \mathrm{~cm}^{-1}$ is indicative of incorporation of $\mathrm{H}_{2} \mathrm{O}$ in the BSG film before and after the diffusion step. Some bonds, e.g., at around $3416 \mathrm{~cm}^{-1}$, are X-O-H bonds commonly formed from weak Si-B bonds. ${ }^{53,55,56,58}$ The cause is possibly a rehydration of the BSG films within minutes after unloading of the wafers from the diffusion furnace, which then renders those B atoms in the BSG as part of the newly formed B-O-H bonds visible for FTIR measurement. A different or even additional explanation can be found in the oxidation enhanced diffusion effect of $\mathrm{B}$ in the presence of $\mathrm{O} .^{62}$ During the high-T step diffusion of $\mathrm{B}$, in the $\mathrm{BSG}$ a formation of compounds with $\mathrm{O}$ atoms can occur enhancing the diffusion in the different layers, including BSG, BRL, and emitter region. In highly doped Si layers ${ }^{62}$ this effect occurs and can especially lead to changes in B bonding sites, i.e., formation of $\mathrm{B}-\mathrm{O}-\mathrm{H}$ bonds as a result.

Fig. 10 displays the change in bond density between non- and as-diffused samples. The normalized FTIR peak area $I_{N}$ is thereby proportional to various aforementioned properties of the BSG and emitter structure. In direct comparison, it shows the overall decrease in $\mathrm{Si}-\mathrm{O}$ bonds at $1084 \mathrm{~cm}^{-1}$ (filled gray squares in Fig. 10) in accordance with the assumption of both an enhanced diffusion of $\mathrm{B}$ by $\mathrm{O}$ in highly doped $\mathrm{Si}^{62}$ i.e., the $\mathrm{BRL}$ and emitter layer and the rearrangement of $\mathrm{B}$ 


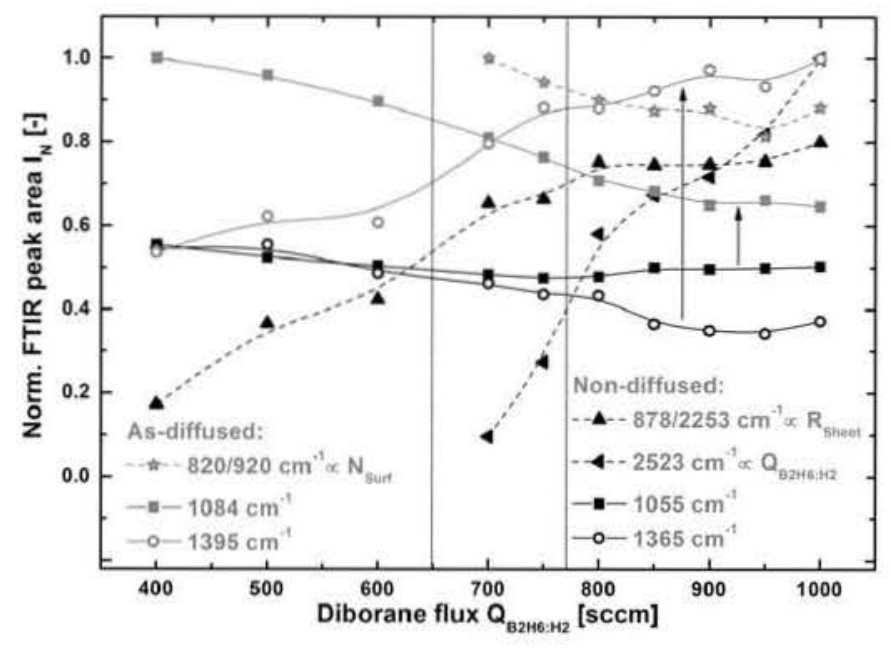

Figure 10. Normalized FTIR peak area $\mathrm{I}_{\mathrm{N}}$ in dependency on $\mathrm{B}_{2} \mathrm{H}_{6}: \mathrm{H}_{2}$ flux $\mathrm{Q}_{\mathrm{B} 2 \mathrm{H} 6 \mathrm{H} 2}$ for as-diffused (gray symbols and guides-to-the-eye) and nondiffused (black symbols and guides-to-the-eye) samples for different FTIR peaks (wavenumber $\tilde{v}$ linked to symbol type).

bonds in the BSG layer, both with increase in $\mathrm{B}_{2} \mathrm{H}_{6}: \mathrm{H}_{2}$ flux. The main (Si-)B-O bond forming at peak center of $1395 \mathrm{~cm}^{-1}$ is more than doubling in intensity (open gray circles in Fig. 10). Further curves include the bonds at peak centers 820 and $920 \mathrm{~cm}^{-1}$ (filled gray stars in Fig. 10) as an indicator of the emitter depth D decrease in region III in comparison to the right upper inset in Fig. 4 (open stars). Since the emitter depth $\mathrm{D}$ behaves in a reciprocal way to the surface concentration $\mathrm{N}_{\text {Surf }}$ (open triangles in right upper inset of Fig. 4), the same can be deduced for the bond density denoted by the peaks at 820 and $920 \mathrm{~cm}^{-1}$. The last two curves for the intensity change of the peaks at 2523 and $2253 \mathrm{~cm}^{-1}$ show a proportionality to the $\mathrm{B}_{2} \mathrm{H}_{6}: \mathrm{H}_{2}$ flux $\mathrm{Q}_{\mathrm{B} 2 \mathrm{H} 6 \mathrm{H} 2}$ indicated by the $\mathrm{B}$ concentration $\mathrm{C}_{\mathrm{ICP}-\mathrm{OES}}$ as well as the sheet resistance $R_{\text {Sheet }}$, respectively. Scaling these curves (see Fig. 11) leads to a perfect match in the various regimes I to III. While in regime I \& II B-O-H/Si-H bonds at peak $2253 \mathrm{~cm}^{-1}$ are primarily formed proportionally to $\mathrm{C}_{\mathrm{ICP}-\mathrm{OES}}$, this changes in regime III when the density of this bond reaches a maximum value proportional to $R_{\text {Sheet }}$, beginning in regime II. The peak area of the bond with a peak at $2253 \mathrm{~cm}^{-1}$ shows in our case a proportionality to the B concentration of the non-diffused samples of

B conc. $\left[\mathrm{cm}^{-3}\right]=(6.80(5) \cdot$ FTIR abs. $) \cdot 10^{20}\left[\mathrm{~cm}^{-3}\right]$

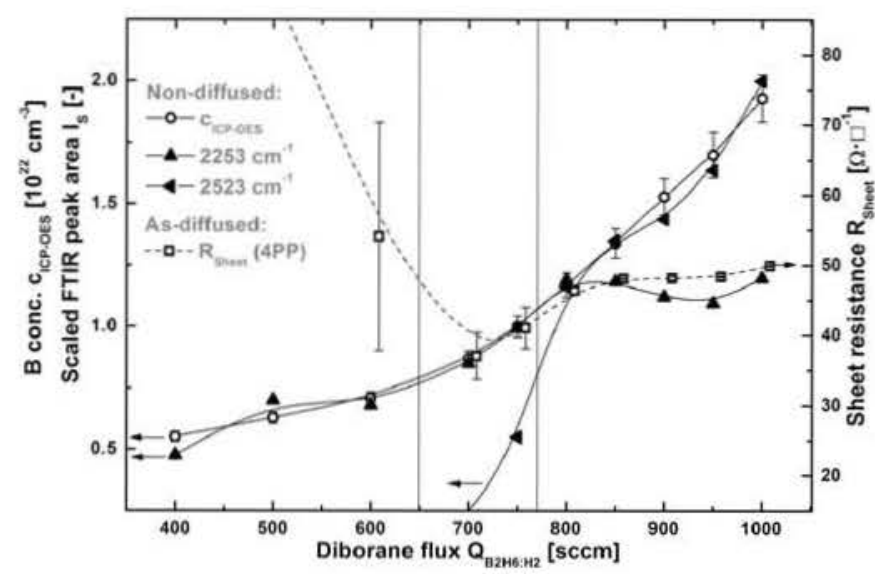

Figure 11. B concentration CICP-OES (open circles, solid guide-to-the-eye) of non-diffused samples and sheet resistance $R_{\text {Sheet }}$ of as-diffused samples (open squares, dashed guide-to-the-eye) in comparison with scaled FTIR peak areas Is of non-diffused (filled symbols, straight guide-to-the-eye) samples in dependency on $\mathrm{B}_{2} \mathrm{H}_{6}: \mathrm{H}_{2}$ flux $\mathrm{Q}_{\mathrm{B} 2 \mathrm{H} 6: \mathrm{H} 2}$.
This formula is limited to regime I \& II and under the condition that the hereby calculated B concentration value is below the one calculated from the peak at $2523 \mathrm{~cm}^{-1}$. At the point where the $\mathrm{Si}-\mathrm{H} / \mathrm{B}-\mathrm{O}-\mathrm{H}$ bonds with their peak at $2253 \mathrm{~cm}^{-1}$ branches from the curve of $\mathrm{C}_{\mathrm{ICP}-\mathrm{OES}}$ the $\mathrm{B}-\mathrm{H}$ bond at $2523 \mathrm{~cm}^{-1}$ takes over and follows

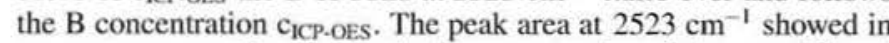
our case a proportionality to the B concentration of the non-diffused samples of

$$
\text { B conc. }\left[\mathrm{cm}^{-3}\right]=(1.25(3) \cdot \text { FTIR abs. }) \cdot 10^{21}\left[\mathrm{~cm}^{-3}\right]
$$

This formula is limited to regime III and under the condition that the hereby calculated $\mathrm{B}$ concentration value is above the one calculated from the peak at $2253 \mathrm{~cm}^{-1}$. Being able to calculate the B concentration of non-diffused samples by FTIR measurement allows for predicting the emitter properties before the actual diffusion step. In as-diffused samples, FTIR measurements can similarly determine emitter properties, that otherwise need to be measured by destructive measurements (e.g., ECV, SIMS, etc.)

\section{Conclusions}

ICP-PECVD as an alternative CVD technique yields BSG films for conventional p-type emitters with unique properties compared to standard gas phase diffusion sources. In this study, we identified three regimes of diborane flux range with different physical behavior depending on B content in the non- or as-diffused layer. Using ICP-OES calibrated FTIR measurements for determining the B concentration in the BSG layers, the microscopic changes within the glass film, i.e., the molecular bond structures, were shown to be the cause for the dependencies of various film and emitter properties. The overall densification and stabilization of the non-diffused BSG films during the high-T step to a subsequent as-diffused layer led to a reduced number of B related bonds, formation of an emitter layer, and in some cases either a depletion layer or BRL on the surface. Most of the former B containing $\mathrm{B}-(\mathrm{O})-\mathrm{H}$ bonds in the as-deposited layers are the source for diffusible $\mathrm{B}$ atoms to form the $\mathrm{B}$ doped layers or rearrange into stable Si-O-B bonds. Depending on pre- or post-diffusion state of the film, different FTIR peak absorption values can be used to determine the $B$ content in the film, e.g., the B-O bond with its peak at $2523 \mathrm{~cm}^{-1}$ for non-diffused BSG films. However, the FTIR spectra of ICP-PECVD BSG films differ from other techniques and process gas mixtures. The formation of a BRL could be related to the high B flux in regime III and a subsequent reduction in emitter depth as a consequence of reduced diffusion on the BSG/Si interface during BRL growth. This correlation can even be predicted using FTIR peak measurements on non-diffused samples. The result is an apparent decrease in emitter sheet resistance and a further increase in recombination of charge carriers near the surface. Using GD-OES, B profiles depicting the accumulation of $\mathrm{B}$ near the interface on both sides forming the BRL support the theory of an enhanced B diffusion at higher B concentrations in the BSG film. Understanding the BRL formation, it can be avoided or removed during further process steps.

\section{Acknowledgments}

The authors thank L. Mahlstaedt and B. Rettenmaier for their support. Part of this work was financially supported by the German Federal Ministry for Economic Affairs and Energy (FKZ 0325581 \& 0324001). The content is the responsibility of the authors.

\section{References}

1. B. K. Maji, H. Jena, and R. Asuvathraman, J. Non-Cryst. Solids, 434, 102 (2016).

2. D. M. Brown and P. R. Kennicott, I. Electrochem. Soc,, 118, 293 (1971).

3. C. S. Fuller and J. A. Ditzenberger, J. Appl. Phys., 25, 1439 (1954).

4. C. S. Fuller and J. A. Ditzenberger. J. Appl. Phys. 27. 544 (1956).

5. A. S. Tenney and J. Wong, J. Chem. Phys, , 56, 5516 (1972).

6. A. Wang. J. Zhao, and M. A. Green, Appl. Phvs. Lett., 57, 602 (1990).

7. S. Wemer, E. Lohmüller, U. Belledin, A. H. G. Vlooswijk, R. C. G. Naber, S. Mack, and A. Wolf, Proceedings of the 3lst EU PVSEC, Hamburg, Germany, 637 (2015). 
8. J. Armand, C. Oliver, B. Semmache, M. Gauthier. A. Foucaran, and Y. Cuminal, Proceedings of the 26th EU PVSEC, Hamburg, Germany, 1309 (2011)

9. M. Nolan, T. Perova, R. A. Moore, and H. S. Gamble, J. Non-Cryst. Solids, 254, 89 (1999).

10. K. Ryu, A. Upadhyaya, V. Upadhyaya, A. Rohatgi, and Y.-W. Ok, Prog. Photovolt: Res. Appl., 23, 119 (2015)

11. G. D. Bagratishvili, R. B. Dzhanelidze, D. A. Jishiashvili, L. V. Piskanovskii, and Z. N. Shiolashvili, Phys. Stat. Sol. (a), 56, 27 (1979).

12. P. Rothhardt, C. Demberger, A. Wolf, and D. Biro, En. Proc., 38, 305 (2013),

13. R. Keding, P. Rothhardt, C. Roters, A. Fallisch, S. Hohage, M. Hofmann, R. Woehl, D. Borchert, and D. Biro, Proceedings of the 27th EU PVSEC, Frankfurt, Germany, 1906 (2012).

14. R. Keding, D. Stüwe, M. Kamp, C. Reichel, A. Wolf, R. Woehl, D. Borchert, H. Reinecke, and D. Biro, IEEE J. Photovoltaics, 3(4), 1236 (2013).

15. P. Rothhardt, S. Meier, C. Demberger, A. Wolf, and D. Biro, En. Proc, 55, 287 (2014).

16. N. Wehmeier, B. Lim, A. Merkle, A. Tempez, S. Legendre, H. Wagner, A. Nowack, T. Dullweber, and P. P. Altermatt, IEEE J. Photovolt., 6, 119 (2016)

17. N. Wehmeier, G. Schraps, H. Wagner, B. Lim, N.-P. Harder, and P. P. Altermatt, Proceedings of the 28th EU PVSEC, Paris, France, 1980 (2013).

18. J. Engelhardt, A. Frey, L. Mahlstaedt, S. Gloger, G. Hahn, and B. Terheiden, En, Proc., 55, 235 (2014)

19. J. Engelhardt, A. Frey, S. Fritz, G. Micard, S. Riegel, G. Hahn, and B. Terheiden, Proceedings of the 31st EU PVSEC, Hamburg, Germany, 351 (2015).

20. A. Frey, J. Engelhardt, S. Fritz, S. Gloger, G. Hahn, and B. Terheiden, Proceedings of the 29th EU PVSEC, Amsterdam, Netherlands, 656 (2014).

21. J. Engelhardt, A. Frey, S. Gloger, G. Hahn, and B. Terheiden, Appl. Phys, Lett., 107, 042102 (2015).

22. K. D. Mackenzie, J. W. Lee, and D. Johnson, in State-of-the-Art-Program on Compound Semiconductors XXX, C. R. Abernathy, A. Baca, D. N. Buckley, K. H. Chen. R. Kopf, and R. E. Sah, Editors, PV 99-4, p. 1, The Electrochemical Society Proceedings Series, Pennington, NJ (1999).

23. B. F. P. Roos, T. Dippell, O. Hohn, P. Wohlfart, B. Beier, B. Veit, M. Siebert, and T. Dullweber, Proceedings of the 27th EU PVSEC, Frankfurt, Germany, 1684 (2012).

24. D. Dergez, J. Schalko, A. Bittner, and U. Schmid, Appl. Surf. Sci., 284, 348 (2013).

25. L. d. S. Zambom. R. D. Mansano, and R. Furlan, Vacuum, 65. 213 (2002).

26. H. P. Zhou, D. Y. Wei, L. X. Xu, Y. N. Guo, S. Q. Xiao, S. Y. Huang, and S. Xu, Appt. Surf. Sci, 264, 21 (2013).

27. A. S. Tenney, J. Electrochem. Soc., 118, 1658 (1971).

28. B. C. Smith, Fundamentals of Fourier transform infrared spectroscopy, p. 10, CRC Press LLC (1996).

29. R. N. Sah and P. H. Brown, Microchem. J., 56, 285 (1997).

30. M. A. Kessler, T. Ohrdes, B. Wolpensinger, and N.-P. Harder, Semicond. Sci. Technol. 25, $055001(2010)$

31. T. L. Aselage, J. Mater. Res., 13, 1786 (1998).
32. I. Kurachi and K. Yoshioka, Jpn. J. Appl. Phys., 53, 036504 (2014).

33. I. Kurachi and K. Yoshioka, Jpn. J. Appl. Phys., 54, 096502 (2015)

34. J. Engelhardt, A. Frey, Y. Schiele, and B. Terheiden, Verfahren zum Herstellen von Solarzellen mit simultan rückgeätzten dotierten Bereichen, Pat. No. DE102014103303A1, March 12th (2014).

35. Y. Schiele, F. Book, C. Demberger, K. Jiang, and G. Hahn, Proceedings of the 29 th EU PVSEC, Amsterdam, Netherlands, 821 (2014).

36. D. E. Kane and R. M. Swanson, Proceedings of the 18th IEEE Photovolt. Spec. Conf. Las Vegas, USA, 578 (1985).

37. J. Engelhardt, G. Hahn, and B. Terheiden, En. Proc., 77, 786 (2015).

38. E. Lohmüller, S. Werner, J. Schön, M. Thanasa, S. Mack, W. Wolke, A. Wolf, F. Clement, and D. Biro, Proceedings of the 28th EU PVSEC, Paris, France, 1043 (2013).

39. A. C. Jones and M. L. Hitchman, Chemical Vapour Deposition: Precursors, Pro cesses and Applications, p. 29, Royal Society of Publishing, Cambridge (2009).

40. K. Seshan, Handbook of Thin Film Deposition Processes and Techniques, 3rd Chapter by J. Foggiato, p. 138, William Andrew Inc. (2001).

41. P. Pichler, Intrinsic Point Defects, Impurities and Diffusion in Silicon, p. 337, Springer-Verlag, Wien (2004).

42. S. Riegel, F. Mutter, G. Hahn, and B. Terheiden, En. Proc., 8, 533 (2011).

43. V. E. Borisenko and S. G. Yudin, Phys. Stat. Sol. (a), 101, 123 (1987).

44. G. L. Vick and K. M. Whittle, J. Electrochem, Soc., 116, 1142 (1969)

45. Y. Sato, K. Ehara, and K. Saito, J. Electrochem. Soc., 136. 1777 (1989).

46. A. S. Grove, O. Leistiko Jr., and C. T. Sah, J. Appl. Phys, ,35, 2695 (1964)

47. M. Becker, U. Gösele, A. Hofmann, and S. Christiansen, J. Appl. Phys., 106, 074515 (2009).

48. S. M. Iftiquar, J. Phvs. D: Appl. Phys, 31, 1630 (1998).

49. J. P. Monat, R. K. Hanson, and C. H. Kruger, Combust. Sci. Technol., 16, 21 (1977).

50. L. F. Spencer and A. D. Gallimore, Plasma Chem. Plasma P., 31, 79 (2011).

51. A. Borghesi, B. Pivac, A. Sassella, and A. Stella, J. Appl. Phys., 77, 4196 (1995).

52. H. J. Hrostowski and R. H. Kaiser, Phys. Rev, 107,966 (1957).

53. F. Ay and A. Aydinli, Opt. Mat., 26, 33 (2004).

54. S. P. A. Osório, I. Montero, J. Perrière, and J. M. Martinez-Duart, Appl. Surf. Sci., 70/71, 772 (1993).

55. E. A. Taft, J. Electochem. Soc., 118, 1985 (1971)

56. A. G. Thorsness and A. J. Muscat, I. Electrochem. Soc., 150, F219 (2003)

57. F. S. Becker, D. Pawlik, H. Schäfer, and G. Staudigl, J. Vac. Sci. Tech. B, 4, 732 (1986).

58. M. Nolan, T. S. Perova, R. A. Moore, C. E. Beitia, J. F. McGilp, and H. S. Gamble, 1. Electrochem. Soc., 147, $3100(2000)$

59. S. C. Shen and M. Cardona, Phys. Rev: B, 23, 5322 (1981).

60. T. Shimanouchi, Tables of Molecular Vibrational Frequencies Consolidated Volume I, p. 36, National Bureau of Standards (1972).

61. M. Tomozawa, Y.-K. Lee, and Y.-L. Peng, I. Non-Cryst. Solids, 242, 104 (1998).

62. D. J. Roth and J. D. Plummer, J. Electrochem. Soc., 141, 1074 (1994). 